\title{
2019 Zuckerkandl Prize
}

\author{
David A. Liberles ${ }^{1}$
}

(c) Springer Science+Business Media, LLC, part of Springer Nature 2019

This year, 2019, marks the first year that the Zuckerkandl Prize has been re-instated. This is an award for the top paper published in Journal of Molecular Evolution to appear in a print issue during the calendar year, as judged by a committee. The award committee consisting of Arturo Becerra (National Autonomous University of Mexico), Erich Bornberg-Bauer (University of Muenster, Germany), Joana Carneiro da Silva (University of Maryland School of Medicine, USA), and Rosa Fregel (University of La Laguna, Spain) was assembled and the entire editorial board was polled for nominations to the committee.

Four papers were nominated and received serious discussion from the committee. These three runners up are listed below and are also papers that reflect important advances and observations in molecular evolution and comparative genomics.

- Gibson and Eyre-Walker, "Investigating Evolutionary Rate Variation in Bacteria" (Gibson and Eyre-Walker 2019).

- Guerin et al., "Stress Adapted Mollusca and Nematoda Exhibit Convergently Expanded Hsp70 and AIG1 Gene Families" (Guerin et al. 2019).

- Wang et al., "Dependency Between Protein-Protein Interactions and Protein Variability and Evolutionary Rates in Vertebrates: Observed Relationships and Stochastic Modeling" (Wang et al. 2019).

I am pleased to announce that "Big on Change, Small on Innovation: Evolutionary Consequences of RNA Sequence Duplication" by Plebanek et al. (2019) is the Zuckerkandl Prize Award winner. This study examines the role of sequence duplications within an RNA molecule on structural and functional diversification. Over short evolutionary periods, they find substantial complexification of the structural repertoire underpinning similar binding functions, but only see limited functional innovation. This work touches on many timely topics, including the role of duplication in innovation, the ease of adaptive biochemical evolution, and the complexity of genotype-phenotype-function mapping over long evolutionary timescales when duplication acts together with point substitution, using a creative model RNA study system. Beyond its generalizability to broader biology, it is also an important study within the RNA in vitro evolution field. Journal of Molecular Evolution is proud to congratulate the authors on this work.

\section{References}

Gibson B, Eyre-Walker A (2019) Investigating evolutionary rate variation in bacteria. J Mol Evol 87(9-10):317-326. https://doi. org/10.1007/s00239-019-09912-5

Guerin MN, Weinstein DJ, Bracht JR (2019) Stress adapted mollusca and nematoda exhibit convergently expanded Hsp70 and AIG1 gene families. J Mol Evol 87(9-10):289-297. https://doi. org/10.1007/s00239-019-09900-9

Plebanek A, Larnerd C, Popović M, Wei C, Pohorille A, Ditzler MA (2019) Big on change, small on innovation: evolutionary consequences of RNA sequence duplication. J Mol Evol 87(7-8):240253. https://doi.org/10.1007/s00239-019-09906-3

Wang X, Branciamore S, Gogoshin G, Rodin AS (2019) Dependency between protein-protein interactions and protein variability and evolutionary rates in vertebrates: observed relationships and stochastic modeling. J Mol Evol 87(4-6):184-198. https://doi. org/10.1007/s00239-019-09899-z

David A. Liberles

tuf77157@temple.edu

1 Department of Biology and Center for Computational Genetics and Genomics, Temple University, Philadelphia, PA 19122, USA 